\title{
Original
}

\section{Effects of Pretreatment with PSK, a Protein-Bound Polysaccharide, on Escherichia Coli Infection in Mice}

\author{
Hiroshi Sakagami ${ }^{1)}$, Kunio Konno ${ }^{1)}$, Yasuo Kurakata ${ }^{2)}$, Minoru Takeda ${ }^{2)}$, \\ Tsuneo Sato ${ }^{2)}$, Hiroshi Harada ${ }^{3)}$, Naomi OHSAWA ${ }^{4)}$, \\ Masato FUJIMAKI ${ }^{4}$ and Nobuhiko Komatsu')
}

\begin{abstract}
Only 17\% of mice inoculated with lethal doses of Escherichia coli survived for 5 days after the challenge. Significant antibacterial activity of PSK, a protein-bound polysaccharide, was induced when the mice were pretreated with $40 \mathrm{mg} / \mathrm{kg}$ of PSK by an intraperitoneal, subcutaneous or intramuscular route, but not by an intravenous route, $48 \mathrm{hr}$ before the $E$. coli inoculation. Repeated oral administration of PSK for 2 weeks $(20 \mathrm{mg} / \mathrm{kg}, 3$ times per week) before $E$. coli inoculation was also effective. Intraperitoneal administration of PSK was most potent, inducing significant polymorphonuclear cell accumulation and generation of luminol-dependent chemiluminescence by peritoneal exudate cells, with a peak $24 \mathrm{hr}$ after administration of the PSK.
\end{abstract}

Key words: PSK, E. coli infection, antibacterial activity, polymorphonuclear cells, chemiluminescence

\section{Introduction}

A protein-bound polysaccharide, PSK, extracted from the mycelium of Coriolus versicolor (Fr.) Quel, has been recognized for its host-mediated antitumor activity. ${ }^{1)}$ However, there are few reports of PSK effects on experimental infections in mice. ${ }^{2,3)}$ To better understand the induction of antibacterial activity, we investigated the effects of PSK administered by various routes on Escherichia coli infection in mice, and the kinetics of the accumulation and activation of the peritoneal exudate cell populations after PSK administration.

\section{Materials and Methods}

Materials. PSK prepared from the mycelium of a CM-101 strain of Coriolus versicolor ${ }^{1)}$ was kindly provided by Kureha Chem. Ind., Ltd., Tokyo.

Mice. Female ICR mice (5 weeks old, 23-25 g) were obtained from Sankyo Labo. Service Co., Tokyo. The mice were used at 6-7 weeks of age.

Antibacterial activity. Each mouse was given a single injection of saline or PSK by one of the indicated administration routes, $48 \mathrm{hr}$ before inoculation with $E$. coli (GN2411) $\left(4 \times 10^{6}\right.$ cells). Survival rates of the mice were determined 5 days after $E$. coli challenge unless otherwise stated. ${ }^{3,4)}$

\footnotetext{
1) First and 2) Second Departments of Biochemistry, Showa University School of Medicine, 1-5-8 Hatanodai, Shinagawa-ku, Tokyo 142, Japan.

3) Department of Haematology, Showa University Fujigaoka Hospital.

4) Public Welfare Institute of Scientific Research Foundation.
} 
Peritoneal exudate cell collection. Mice were killed by decapitation and peritoneal fluid was withdrawn through a 22-gauge needle inserted into the cavity. The content of total polymorphonuclear cells (PMN) in the fluid was determined by the following formula: PMN content $=\mathrm{A} \times \mathrm{B}$; where $\mathrm{A}$ was the total cell number in the peritoneal fluid, determined with a hemocytometer, and B was the percent of PMN in all of the cells, assessed on Cytospinslides (Shandon Southern Products Ltd., Astmoor, England) stained with May-GrunwaldGiemsa (Merck, Darmstadt, West Germany).

Chemiluminescence assay. The peritoneal exudate cells $\left(1 \times 10^{6}\right)$ were mixed with $1.25 \mathrm{mg}$ of opsonized zymosan A (Sigma, St. Louis, MO, USA) and $20 \mu \mathrm{g}$ of luminol (Tokyo Kasei Kogyo Co., Ltd., Tokyo) in $0.6 \mathrm{ml}$ of Eagle's MEM medium without phenol red (Nissui Pharm. Co., Ltd., Tokyo). Light emission was measured at $37^{\circ} \mathrm{C}$ immediately, and at 3 minute intervals over a 15 minute period, with the aid of an Aloka BLR-102 luminescence reader (Aloka Ltd., Tokyo) equipped with a controller. The chemiluminescence values were given as peak cpm instead of integral cpm. ${ }^{4,5}$

\section{Results and Discussion}

When mice were inoculated with about $4 \times 10^{6}$ cells of $E$. coli, only $17 \%$ survived after 1 day (Fig. 1). However, if pretreated intraperitoneally with $40 \mathrm{mg} / \mathrm{kg}$ PSK 2 days before the $E$. coli challenge, the survival ratio increased to $80 \%$. Since the survival ratio of the pretreated mice became stable 5 days after the $E$. coli challenge, the antibacterial activity was assayed at that time. The optimal concentration of PSK was $40 \mathrm{mg} / \mathrm{kg}$ (Figs. 1 and 2); doses greater than this were less effective. The induction of antibacterial activity also depended on the treatment time (Fig. 2). The effect of PSK became detectable $4 \mathrm{hr}$ after treatment, reached a maximum after 1-3 days and then declined almost to the control level.

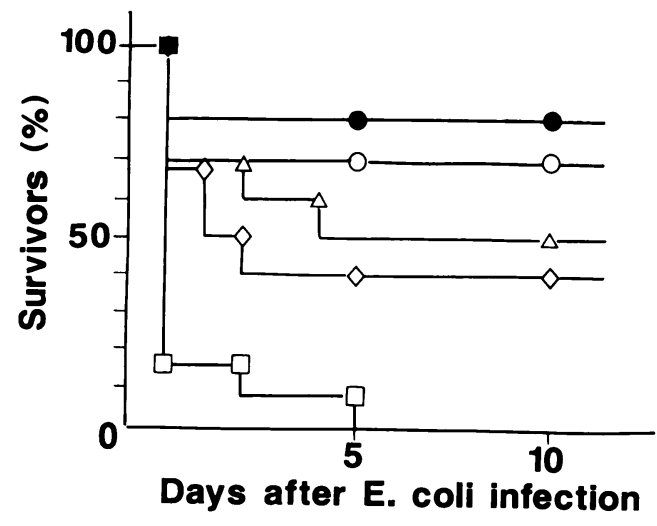

Fig. 1 .

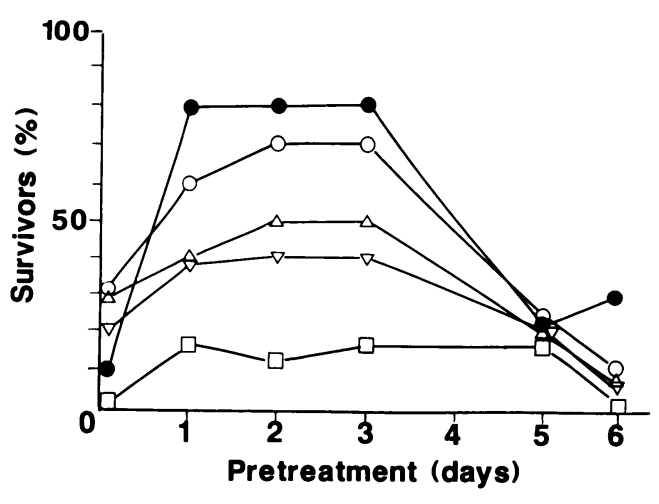

Fig. 2.

Fig. 1. Dose-dependent inhibition of $E$. coli infection by PSK administration. Mice (10-12/group) were intraperitoneally administered $0(\square), 2(\triangle), 8(0), 40$ $(\bullet)$ or $80(\diamond) \mathrm{mg} / \mathrm{kg}$ PSK, $48 \mathrm{hr}$ before $E$. coli challenge. Survival rates were determined at the indicated days after $E$. coli challenge.

Fig. 2. Dependence of inhibition of $E$. coli infection on time of treatment with PSK. Mice (10-12/group) were intraperitoneally administered $0(\square), 0.4(\nabla), 2(\triangle), 8$ $(\bigcirc)$ or $40(\bullet) \mathrm{mg} / \mathrm{kg}$ PSK for the indicated periods before $E$. coli challenge. Survival rate was determined 5 days after $E$. coli challenge. 
Table 1 shows that significant antibacterial activity of PSK was induced when the mice were administered $40 \mathrm{mg} / \mathrm{kg}$ PSK by either an intraperitoneal, subcutaneous, or intramuscular route (Exp. I), but not by an intravenous route (Exp. II), $48 \mathrm{hr}$ before E. coli inoculation. The most potent effect was produced by an intraperitoneal administration of PSK. It should be noted that repeated oral administration of PSK for 2 weeks $(20 \mathrm{mg} / \mathrm{kg}, 3$ times per week) before $E$. coli inoculation was effective (Table 1, Exp. III).

Intraperitoneal administration of PSK induced significant accumulation of polymorphonuclear cells (PMN) (Fig. 3A) and stimulated the generation of luminol-dependent chemiluminescence (LDCL) by peritoneal exudate cells (Fig. 3B). Both the number of PMN and the LDCL generation of the peritoneal exudate cells increased to a peak at $24 \mathrm{hr}$ after PSK

Table 1. Effect of administration routes on PSK inhibition of E. coli infection.

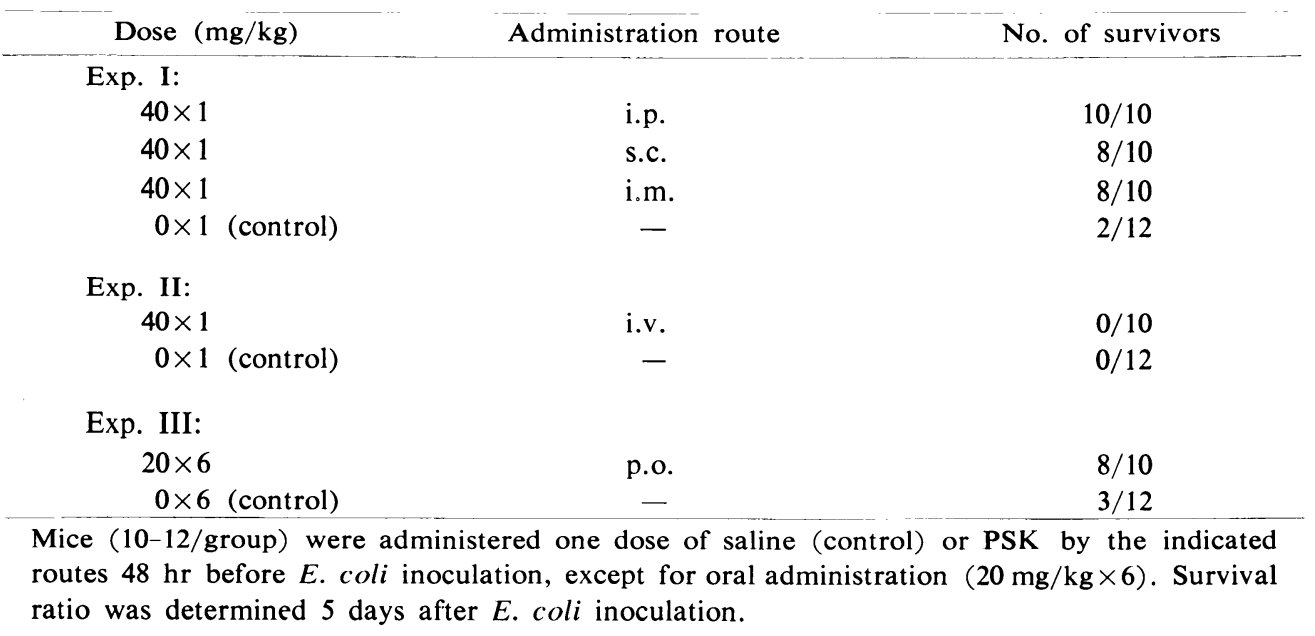
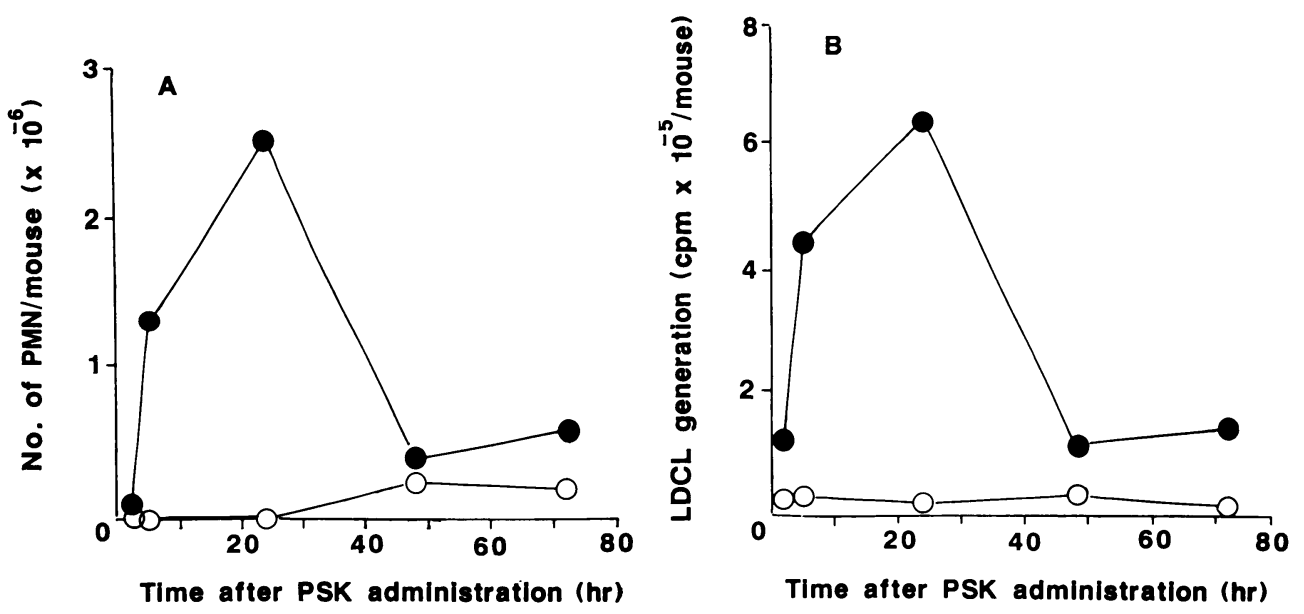

Fig. 3. Time course of PMN accumulation in the peritoneal cavity (A), and LDCL generation by peritoneal exudate cells (B) after intraperitoneal administration of 0 (○) or $40(\bullet) \mathrm{mg} / \mathrm{kg}$ PSK.

Each value is mean from 2 mice. S.D. $<20 \%$. 
administration, and then declined almost to the control level at $48 \mathrm{hr}$.

We observed the lethal effect of $E$. coli infection within 4 days after challenge, and intraperitoneal administration of PSK significantly reduced this lethal effect (Fig. 1). Since PSK induced rapid accumulation of PMN, which had higher LDCL generating activity (Fig. 3), it is highly probable that PSK-induced PMN might be responsible for the rapid disappearance of $E$. coli, especially in the early stages $(0-48 \mathrm{hr})$ after PSK administration. A potential role of PMN was further supported by our finding that intravenous administration of $40 \mathrm{mg}$ / $\mathrm{kg}$ PSK failed to inhibit $E$. coli infection in mice (Table 1, Exp. II) or to stimulate LDCL generation by the peritoneal exudate cells $(9,400 \mathrm{cpm} /$ mouse (PSK treated) vs $19,700 \mathrm{cpm} /$ mouse (control) (data not shown).

The PSK was a mixture of at least four subfractions, each with distinct molecular weight ${ }^{(i)}$ and isoelectric point. ${ }^{i)}$ We previously reported that the highest molecular weight PSK subfraction $(\mathrm{MW}>200 \mathrm{kD}$ ), which induced more potent antibacterial activity in mice than the other lower molecular weight subfractions, also more greatly stimulated LDCL generation by peritoneal exudate cells. ${ }^{3)}$ Further study is necessary to elucidate the mechanism of antimicrobial activity induction by these PSK fractions.

\section{Acknowledgments}

We thank Prof. T. Shimamura for valuable discussion, Prof. S. Inokuchi for encouragement throughout this study and Dr. A. Simpson for help with the manuscript. This study was supported in part by a Grantin-Aid from the Ministry of Education, Science and Culture of Japan, and by the SHORAI Foundation for Science and Technology.

\section{References}

1) Tsukagoshi S, Hashimoto Y, Fujii G, Kobayashi H, Nomoto K and Orita K: Krestin (PSK). Cancer Treat Rev, 11: 131-155 (1984)

2) Mayer $P$ and Drews $J$ : The effect of a protein-bound polysaccharide from Coriolus versicolor on immunological parameters and experimental infections in mice. Infection, 8: 13-21 (1980)

3) Harada H, Sakagami H, Konno K, Sato T, Ohsawa N, Fujimaki M and Komatsu N: Antimicrobial activity induction by PSK subfractions: Dependence on molecular weight. Infection, 17: 38-39 (1989)

4) Harada H, Sakagami H, Konno K, Sato T, Ohsawa N, Fujimaki $M$ and Komatsu N: Induction of antimicrobial activity by antitumor substances from pine cone extract of Pinus parviflora Sieb. et Zucc. Anticancer Res, 8: 581-588 (1988)

5) Allen RC, Stjernhorm RL and Steele RH: Evidence for generation of an electronic excitation state(s) in human polymorphonuclear leukocytes and its participation in bactericidal activity. Biochem Biophys Res Commun, 47: 679-684 (1972)

6) Tsuchitani T, Nio Y, Imai S, Shiraichi T, Kan N, Ohgaki K and Tobe T: Effects of oral administration of PSK on immune responses. I. Correlation of in vivo effects with in vitro biological activities. J Jpn Soc Cancer Ther, 22: 1195-1202 (1987) (in Japanese)

7) Hirase S: Structure and property of PSK. In: PSK (Krestin), Kimura K (Ed), Excerpta Medica, Tokyo, pp 3-18 (1988) (in Japanese)

[Received August 31, 1989: Accepted February 10, 1990] 